\title{
The changing picture of object substitution masking: reply to Di Lollo (2014)
}

\section{Endel Põder* \\ Department of Experimental Psychology, Institute of Psychology, University of Tartu, Tartu, Estonia \\ *Correspondence: endel.poder@ut.ee}

Edited by:

Bruno Breitmeyer, University of Houston, USA

Reviewed by:

Greg Francis, Purdue University, USA

Bruce Bridgeman, University of California, Santa Cruz, USA

Keywords: visual masking, object substitution, attention, modeling, reentrant, feed-forward

In his recent comment, Di Lollo (2014) criticizes my proposal (Põder, 2013) that the attentional gating model (Reeves and Sperling, 1986; Sperling and Weichselgartner, 1995) might be the most simple and reasonable explanation for the results of object substitution masking (OSM) experiments. He argues that OSM cannot be explained without a reentrant hypotheses-testing mechanism (as proposed in Di Lollo et al., 2000). A closer look at his arguments reveals that they are partly based on an inaccurate interpretation of my study, and partly, on some highly problematic assumptions about visual processing.

The goal of my study (Põder, 2013) was to understand the mechanisms behind the results of a typical OSM experiment with varied duration of masker and setsize. There were two main points in my study that are relevant in the present context. First, I analyzed the computational model (CMOS) proposed by Di Lollo et al. (2000) and found it to be identical with the attentional gating model, which has no direct relationship with any kind of "reentrant processing." Second, I proposed an improved mechanism of attention to be combined with this model (or other possible masking models). I have never proposed or tested any new model of masking.

Di Lollo (2014) seems to have a rather subjective view of my study. He criticizes something named Põder's feed-forward account (or model) of OSM, which is supposedly based on two assumptions: reduction of signal to noise ratio (SNR) as a result of integrated noise from the masker, and delayed deployment of attention. Both assumptions are declared to be wrong or at least unjustified.

As I mentioned, I have not built a new model of OSM but just reinterpreted Di Lollo et al.'s (2000) CMOS. Therefore, these assumptions can only be the assumptions underlying CMOS, and actually, they are. I believe that CMOS was a reasonably good model for OSM experiments and that its main assumptions cannot be fundamentally wrong. However, Di Lollo (2014) missed some possibly important details. In CMOS, SNR was reduced not only because of accumulating "noise" from the masker but also because of decay of the target signal. Neither Di Lollo et al. (2000) nor Põder (2013) supposed that SNR is proportional (or inversely proportional) to the duration of the masker.

The model that was tested in my study tried to explain the set-size effects better than the simple attention deployment mechanism used in CMOS. My model assumes that the set-size effect is caused by an initial stage of divided attention. In this model masking per se is independent of set-size. A similar idea about the invariance of masking to set-size was independently discovered by Argyropoulos et al. (2013). My model with divided attention goes a bit further and proposes a plausible explanation for the observed set size effects.

Having explained away the set-size effect, a simple masking effect remains. In my study (Põder, 2013), I did not attempt to reveal its exact mechanisms. I indicated that the combination of the decay of the target signal, integration of the masker signal, and a delayed attention as implemented in CMOS (Di Lollo et al., 2000) might do the job. However, there are many other possibilities. After the removal of the burden to explain set-size effects, the classic models of masking (Weisstein, 1968; Bridgeman, 1971; Francis, 1997) that were analyzed in Francis and Hermens (2002) become fully applicable for OSM (note that the unsatisfactory modeling of attention/set-size effects was the main problem with these models; Di Lollo et al., 2002). Of course, Di Lollo's reentrant hypotheses-testing idea can be included in the candidate list too, as well as Bachmann's (1994) non-specific amplification idea. Hopefully, future studies will be able to discriminate between these models.

Although the set-size effect has been quite convincingly separated from the masking effect, some role of attention in OSM is still not excluded. In a recent study, Pilling et al. (2014) found a modest effect of spatial pre-cueing in one out of the five experiments. Up to now, nobody has explained away the position uncertainty and pre-cueing effects reported in earlier studies (Enns and Di Lollo, 1997; Neill et al., 2002; Tata and Giaschi, 2004; Luiga and Bachmann, 2007). If attention is still important then the models of masking developed by Smith et al. (Smith and Wolfgang, 2004; Smith et al., 2009) or by Bridgeman (2007) may be considered.

Di Lollo (2014) mainly argues against a CMOS-like masking account, but apparently supposes that any kind of essentially feed-forward model cannot explain masking with a sparse trailing masker. The majority of his arguments are based 
on a quite strange view on the visual system. Di Lollo (2014) seems to ignore the hierarchical nature of visual processing and assume that all the maskingrelated processes should occur at some low-level retinotopic layer. Therefore, only retinotopic picture-level noise, integration, and masking are possible. The real visual system consists of at least 4-5 (possibly more) processing levels (e.g., DeYoe and van Essen, 1988; Riesenhuber and Poggio, 1999). The target and masker signals are processed and temporally and spatially integrated throughout this hierarchy. Thus, the "noise" from irrelevant stimuli may interact with relevant signals at any level of processing. The higher levels are increasingly invariant to spatial positions and combine all visual features including motion. It is therefore not surprising at all that the dots far from the target, or a masker that was retinotopically moved away from the target location (Lleras and Moore, 2003), can still interact at higher object recognition levels. Note that the higher-level masking does not need anything like sending perceptual hypotheses back to the lower levels.

A large part of Di Lollo's (2014) critique is directed against using SNR in the models of OSM (although the idea itself was introduced by Di Lollo et al., 2000). Di Lollo (2014) argues that a noisy representation of visual objects is not consistent with the phenomenal experience of not seeing them as noisy pictures; and with clearly different effects of the external pixel noise compared to fourdot masker. His arguments apparently challenge some points of traditional psychophysics. In usual psychophysical models (e.g., Macmillan and Creelman, 2005), noise is a random trial-by-trial variability of internal representations that causes incorrect perceptual decisions. This noise can make a letter A look like a letter B, or like a chicken, or like a blank screen, in some trials. We can manipulate this noise (or SNR) by varying stimulus contrast, size, or exposure duration, presenting distractors, or forward or backward maskers, pre-cueing attention, simultaneous eye movements, etc., besides adding external pixel noise. There is no reason to suppose that the decision-level noise should be visible and look like noise within a single image.
New studies have forced Di Lollo and colleagues to make some changes to their theory. The original account of OSM (Di Lollo et al., 2000) was heavily based on both reentrant hypotheses testing and deployment of attention. The Argyropoulos et al. (2013) results indicated that something is wrong with this theory. The simplest way out was to leave out attention. However, attention had a key role in CMOS and in the predictions related to the Di Lollo et al. (2000) theory. Jannati et al. (2013) found an innovative solution. Nominally, they removed attention but attributed its properties to "reentrant processing." In the original model (Di Lollo et al., 2000), the reentrant processing was supposed to be perpetual generation and testing perceptual hypotheses with periodicity of about $13 \mathrm{~ms}$. In their new account (Jannati et al., 2013), the reentrance "arrives" at about $80-120 \mathrm{~ms}$ after stimulus onset, a typical delay of focusing spatial attention (e.g., Cheal and Lyon, 1991). Overall, their revised theory still follows the attentional gating logic of CMOS. At the same time, they claim that their experiment falsifies the attentional gating account of OSM. A closer look at their arguments reveals that their description of the "attentional gating model" does not contain attention at all. It is not surprising that such a model cannot fit any (old or new) experimental results.

In conclusion, I would describe the present situation as follows. The attentional gating idea effectively explained the effects of attention and simplified the problem of OSM tremendously. Now, one may take a single target stimulus with a common-onset masker and present them at a fixed position of the visual field, with full attention available, and try to observe OSM. There is a chance that $\mathrm{Di}$ Lollo (or somebody else) can demonstrate the action of reentrant hypotheses-testing mechanism in that simple experiment. It would be an interesting and surprising (at least for me) finding. But it would not contradict my attentional gating account of OSM experiments with set-size variation.

\section{REFERENCES}

Argyropoulos, Y., Gellatly, A., Pilling, M., and Carter, W. (2013). Set size and mask duration do not interact in object-substitution masking. J. Exp. Psychol. Hum. Percept. Perform. 39, 646-661. doi: 10.1037/a0030240
Bachmann, T. (1994). Psychophysiology of Visual Masking: The Fine Structure of Conscious Experience. Commack, NY: Nova Science.

Bridgeman, B. (1971). Metacontrast and lateral inhibition. Psychol. Rev. 78, 528-539. doi: $10.1037 / \mathrm{h} 0031782$

Bridgeman, B. (2007). Common-onset masking simulated with a distributed-code model. Adv. Cogn. Psychol. 3, 33-40. doi: 10.2478/v10053-008-0012-5

Cheal, M. L., and Lyon, D. R. (1991). Central and peripheral precuing of forced-choice discrimination. Q. J. Exp. Psychol. 43A, 859-880. doi: 10.1080/14640749108400960

DeYoe, E. A., and van Essen, D. C. (1988). Concurrent processing streams in monkey visual cortex. Trends Neurosci. 5, 219-226. doi: 10.1016/01662236(88)90130-0

Di Lollo, V. (2014). Reentrant processing mediates Object Substitution Masking: comment on Põder (2013). Front. Psychol. 5:819. doi: 10.3389/fpsyg.2014.00819

Di Lollo, V., Enns, J. T., and Rensink, R. A. (2000). Competition for consciousness among visual events: the psychophysics of reentrant visual processes. J. Exp. Psychol. Gen. 129, 481-507. doi: 10.1037/0096-3445.129.4.481

Di Lollo, V., Enns, J. T., and Rensink, R. A. (2002) Object substitution without reentry? J. Exp. Psychol. Gen. 131, 594-596. doi: 10.1037/00963445.131.4.594

Enns, J. T., and Di Lollo, V. (1997). Object substitution: a new form of visual masking in unattended visual locations. Psychol. Sci. 8, 135-139. doi: 10.1111/j.1467-9280.1997.tb00696.x

Francis, G. (1997). Cortical dynamics of lateral inhibition: metacontrast masking. Psychol. Rev. 104, 572-594. doi: 10.1037/0033-295X.104.3.572

Francis, G., and Hermens, F. (2002). Comment on "Competition for consciousness among visual events: the psychophysics of reentrant visual processes" (Di Lollo, Enns, and Rensink, 2000). J. Exp. Psychol. Gen. 131, 590-593. doi: 10.1037/00963445.131.4.590

Jannati, A., Spalek, T. M., and Di Lollo, V. (2013). A novel paradigm reveals the role of reentrant visual processes in object substitution masking. Atten. Percept. Psychophys. 75, 1118-1127. doi: 10.3758/s13414-013-0462-9

Lleras, A., and Moore, C. M. (2003). When the target becomes the mask: using apparent motion to isolate the object-level component of object substitution masking. J. Exp. Psychol. Hum. Percept. Perform. 29, 106-120. doi: 10.1037/00961523.29.1.106

Luiga, I., and Bachmann, T. (2007). Different effects of the two types of spatial pre-cueing: what precisely is “attention” in Di Lollo's and Enns' substitution masking theory? Psychol. Res. 71, 634-640. doi: 10.1007/s00426-006-0052-8

Macmillan, N. A., and Creelman, C. D. (2005) Detection Theory: A User's Guide, 2nd Edn. New York, NY; London: Lawrence Erlbaum Associates.

Neill, W. T., Hutchison, K. A., and Graves, D. F. (2002). Masking by object substitution: dissociation of masking and cuing effects. J. Exp. Psychol. Hum. Percept. Perform. 28, 682-694. doi: 10.1037/00961523.28.3.682

Pilling, M., Gellatly, A., Argyropoulos, Y., and Skarratt, P. (2014). Exogenous spatial precuing 
reliably modulates object processing but not object substitution masking. Atten. Percept. Psychophys. doi: $10.3758 / \mathrm{s} 13414-014-0661-z$

Põder, E. (2013). Attentional gating models of object substitution masking. J. Exp. Psychol. Gen. 142, 1130-1141. doi: 10.1037/a0030575

Reeves, A., and Sperling, G. (1986). Attention gating in short-term visual memory. Psychol. Rev. 93, 180-206. doi: 10.1037/0033-295X. 93.2.180

Riesenhuber, M., and Poggio, T. (1999). Hierarchical models of object recognition in cortex. Nat. Neurosci. 2, 1019-1025. doi: 10.1038/ 14819

Smith, P. L., Lee, Y.-E., Wolfgang, B. J., and Ratcliff, R. (2009). Attention and the detection of masked radial frequency patterns: data and model. Vision Res. 49, 1363-1377. doi: 10.1016/j.visres.2008.04.024
Smith, P. L., and Wolfgang, B. J. (2004). The attentional dynamics of masked detection. J. Exp. Psychol. Hum. Percept. Perform. 30, 119-136. doi: 10.1037/0096-1523. 30.1.119

Sperling, G., and Weichselgartner, E. (1995). Episodic theory of the dynamics of spatial attention. Psychol. Rev. 102, 503-532 doi: 10.1037/0033295X.102.3.503

Tata, M. S., and Giaschi, D. E. (2004). Warning: attending to a mask may be hazardous to your perception. Psychon. Bull. Rev. 11, 262-268. doi: 10.3758/BF03196568

Weisstein, N. (1968). A Rashevsky-Landahl neural net: simulation of metacontrast. Psychol. Rev. 75, 494-521. doi: 10.1037/h0026769

Conflict of Interest Statement: The author declares that the research was conducted in the absence of any commercial or financial relationships that could be construed as a potential conflict of interest.

Received: 29 July 2014; accepted: 22 August 2014; published online: 09 September 2014.

Citation: Põder E (2014) The changing picture of object substitution masking: reply to Di Lollo (2014). Front. Psychol. 5:1004. doi: 10.3389/fpsyg.2014.01004

This article was submitted to Perception Science, a section of the journal Frontiers in Psychology.

Copyright () 2014 Põder. This is an open-access article distributed under the terms of the Creative Commons Attribution License (CC BY). The use, distribution or reproduction in other forums is permitted, provided the original author(s) or licensor are credited and that the original publication in this journal is cited, in accordance with accepted academic practice. No use, distribution or reproduction is permitted which does not comply with these terms. 